\title{
Characteristics of Tibetan Color Painting Art and Its Application in the Design of Street Furniture
}

\author{
Yilei Zhao \\ Art College of Southwest Minzu University, Chengdu, China \\ Email:695046753@qq.com
}

How to cite this paper: Zhao, Y.L. (2019) Characteristics of Tibetan Color Painting Art and Its Application in the Design of Street Furniture. Open Journal of Social Sciences, 7, 42-51.

https://doi.org/10.4236/jss.2019.74004

Received: February 28, 2019

Accepted: April 8, 2019

Published: April 11, 2019

Copyright $\odot 2019$ by author(s) and Scientific Research Publishing Inc. This work is licensed under the Creative Commons Attribution International License (CC BY 4.0).

http://creativecommons.org/licenses/by/4.0/

\begin{abstract}
First, this paper sorts out the theme types and patterns of Tibetan architectural colored paintings, and analyzes the artistic characteristics of Tibetan color paintings. On this basis, it focuses on studying the artistic ways to enhance the scope of Tibetan color painting art, and elaborates on the application of traditional color painting art in the design of street furniture in accordance with the current situation of urban and environmental development in Tibetan areas, so as to help to promote the regional style of urban environment in Tibetan areas.
\end{abstract}

\section{Keywords}

Tibetan Color Paintings, Street Furniture, Design

\section{Literature Review}

\subsection{Research Background}

Since modern times, China's urban planning and construction of urban supporting facilities have shown a trend of convergence, divorcing from the urban environment and neglecting the regional culture, so that all cities in China are designed in the same way. Designers have not fully tapped the unique culture of the city, but destroyed the different image temperament of each city. In urban construction and planning, street furniture, as an indispensable facility of urban public space, bears the important task of shaping regional cultural landscape in cities, and systematic planning and design of street furniture are one of the effective ways to enhance the image of the urban landscape. 


\subsection{Current Research}

At present, most of the research on Tibetan color painting art has deeper basic research on its religious connotation, or it is applied to Tibetan architectural design and interior design research of Tibetan dwellings. At the same time, most of the foreign academic research on urban furniture is in cities with better public infrastructure, and it does not involve areas with underdeveloped public facilities, such as Tibetan cities. Therefore, the following will explore a variety of artistic approaches to enhance the development of Tibetan painting art, and explore the application of traditional painting art in the design of "street furniture" in light of the current development of urban environment in Tibetan areas.

\section{Forms of Tibetan Architectural Colored Paintings}

Architectural colored paintings are decorative patterns drawn on the timber components of buildings. It is not only an effective way to protect building components, but also an important reflection of people's world outlook and values. Tibetan people mainly live in the Qinghai-Tibet Plateau and its surrounding areas, and have bred a unique Tibetan culture in a unique natural environment. As one of the carriers of Tibetan culture, Tibetan architecture embodies the unique artistic characteristics of the Tibetan nationality. Tibetan architectural decoration has a long history of development, and one of the most important decorative techniques is color painting. Tibetan color paintings can be classified into the following types.

\subsection{Geometric Pattern}

Since the Neolithic Age, Tibetan people have decorated objects with geometric patterns, which seem simple but actually contain and convey rich information. Common geometric figures include stripe (Figure 1), T-shaped pattern (Figure 2), fret, and chequered pattern and so on. There are two structures of single drawing and continuous drawing [1]. It is often drawn on doors, windows, beams and curtains. In addition, there are also geometric animal patterns like dog-nose pattern (Figure 3), and geometric auspicious patterns like Ruyi pattern (Figure 4), which are often drawn on the column cap, beams, brackets and rafters and other building components.

\subsection{Animal Patterns}

Tibetan culture holds that all things in the world are spiritual, and the concept of

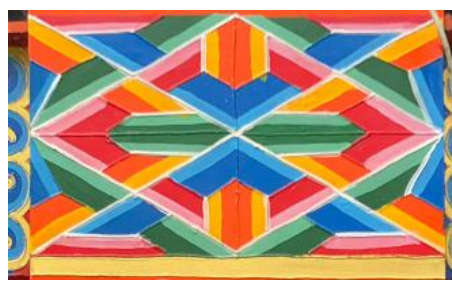

Figure 1. Stripe. 
animal cult has permeated all aspects of life. Animal patterns in architectural decoration can be divided into two types of real animals and fictitious animals. The patterns of real animals include fish (Figure 5), double-head duck and other animals, and the patterns of fictitious animals include Ziba (Figure 6), the head of the legendary turtle, phoenix (Figure 7) and dragon (Figure 8), which are mainly drawn on doors, windows, beams and other building components in pairs. It is strong in color contrast, high in color purity and simple in model, highly summarizing the characteristics of the animal image. There are lotus flowers, branches and leaves around [2].

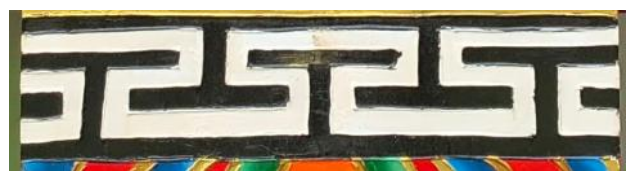

Figure 2. T-shaped pattern.

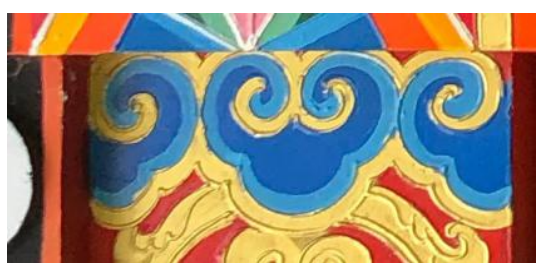

Figure 3. Dog-nose pattern.

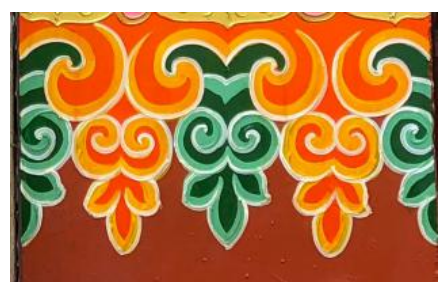

Figure 4. Ruyi pattern.

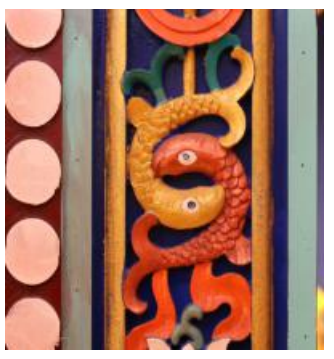

Figure 5. Fish.

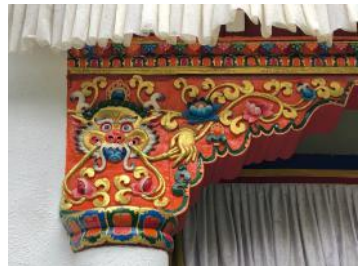

Figure 6. Ziba. 


\subsection{Plant Patterns}

The plant patterns in Tibetan color paintings are refined on their image, and are embodied as simplified and non-realistic plane figures in architectural decoration, which describe a picture of abundant products and prosperity, so as to promote believers to yearn for a better spiritual world. The plant patterns include curling grass pattern (Figure 9), lotus pattern (Figure 10), epiphyllum pattern, pomegranate pattern and peach pattern, which are often drawn on doors, windows, and beams, columns, brackets and rafters and other building components.

\subsection{Buddha Patterns}

Buddha patterns are mainly drawn in temple buildings. In the $7^{\text {th }}$ century, Buddhism was introduced into the Qinghai-Tibet Plateau via India and Nepal, and spread rapidly. The number of believers in Buddhism gradually surpassed that in Bon religion, the native religion. Hundreds of years later, a number of sects arose, among which Nyingma, Bka'-gdems-pa, Sakya, Bka'-brgyud-pa and Gelug are the most prosperous. During the reign of Srongtsen Gampo, Buddhist monasteries were built in large numbers, and each sect had its own main monastery. In the later stage, the decorative patterns of monasteries have been enriched through the continuous renovation and expansion of the monks.

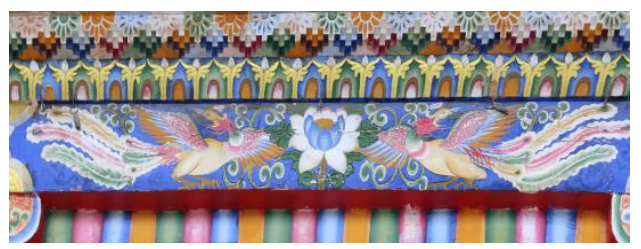

Figure 7. Phoenix.

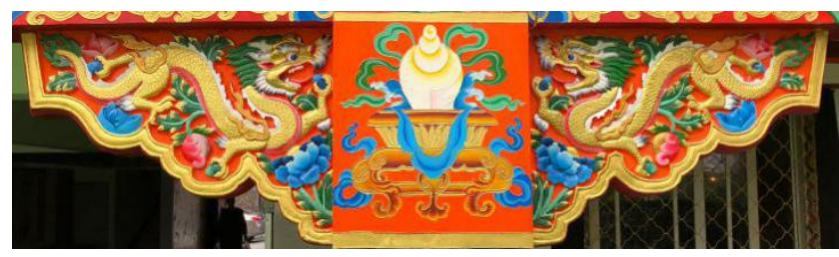

Figure 8. Dragon.

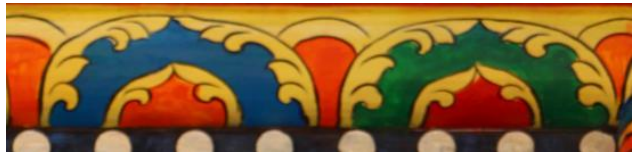

Figure 9. Curling grass pattern.

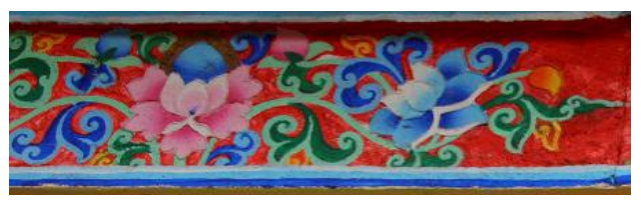

Figure 10. Lotus pattern. 
Buddha patterns embody the important role of sect propaganda and play a decisive role in decorative art of Tibetan Buddhist paintings. Buddha patterns mainly appear in the arches, brackets, rafters and ceilings of the building components and the patterns are well-posed with cool expressions. Patterns are painted in a single color, often with a single white line (Figure 11) [3].

\subsection{Patterns of Buddhist Objects}

In the decoration of architectural colored paintings of Buddhist monasteries in Tibetan areas, Buddhist objects and instruments are also painted on building components as decorative contents to increase the religious atmosphere of the site. Text paintings are mainly based on Sanskrit (Figure 12), with the contents of Om Mani Padme Hum, the character of Zhangga, the character of “厉”, the character of "Kalachakra" (Figure 13) and their combined figures. The instruments include vajra pestle (Figure 14), dorje phurba, vajra bell and Vajra Tomahawk and so on. In addition, there are also the common patterns in the Tibetan Buddhism, such as the Seven Jewels of a Cakravartin King (Ratna-Chakra, Empress, Divine Jewellery, Immense Wealth, Huge Army of War-Chariots, Huge Army of Cavalry and Huge Army of Elephants), eight lucky images (darpana, gorochana, dadhi, dyrva, bilva, dakshinavarta-shankha, sindura and sarshapa), as well as the eight auspicious symbols (shankha, kalasha, chattra, shrivatsa, chakra, survana matsya, padma, dhvaja) (Figure 15), as well as stacked sutras(Figure 16) and Xixuan (Figure 17) and so on [4].

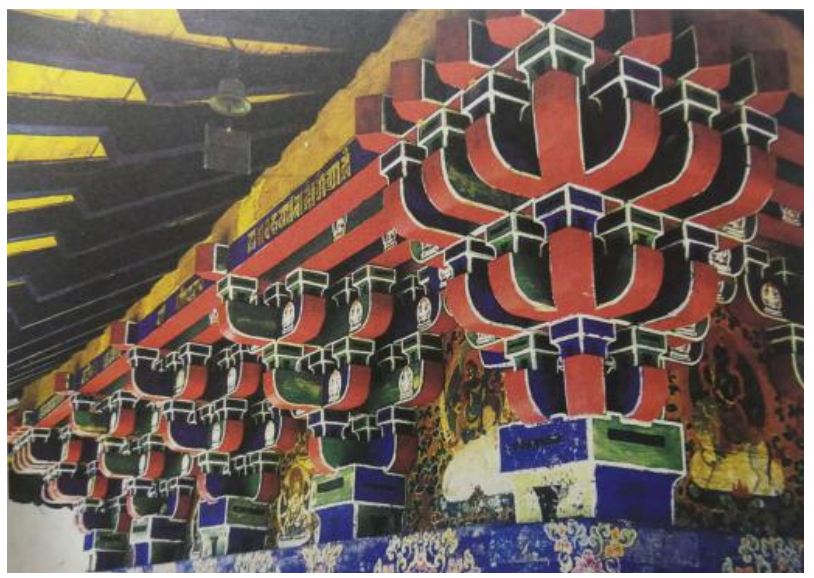

Figure 11. Buddha statues in components.

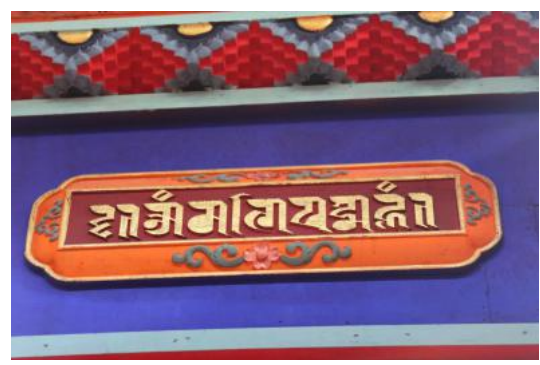

Figure 12. Sanskrit in color paintings. 


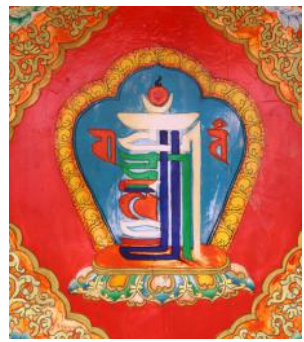

Figure 13. Kalachakra figure.

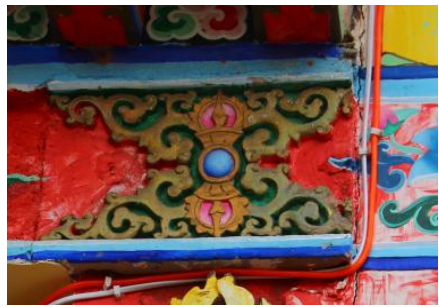

Figure 14. Vajra pestle.

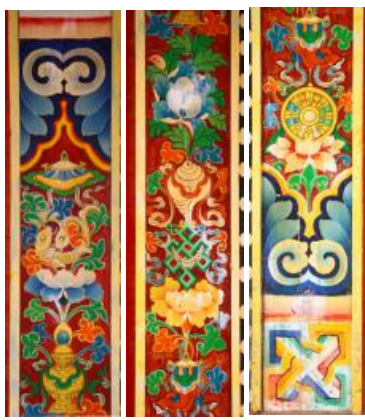

Figure 15. Eight auspicious symbols.

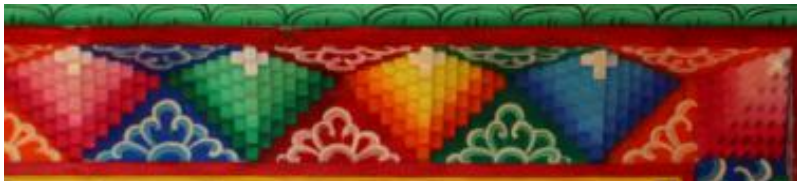

Figure 16. Stacked sutras.

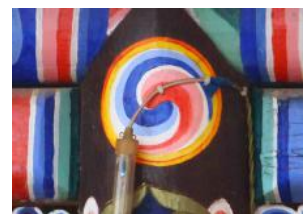

Figure 17. Xixuan.

\subsection{Patterns of Natural Scenery}

Patterns of natural scenery include flame pattern (Figure 18), cloud pattern (Figure 19), sun and moon pattern, mountain pattern and water pattern, which are closely linked with the living environment of the Tibetan people. They live on the Qinghai-Tibet Plateau, where there are a large number of mountains with ever-changing clouds. The people draw life scenes in color paintings, which can 
lead to unlimited reverie.

\section{Artistic Characteristics of Tibetan Architectural Colored Paintings}

\subsection{Bright Colors}

Tibetan architectural colored paintings are painted with mineral pigments, which high purity of color. Painters directly draw color paintings with raw materials, thus forming rich colors and strong contract on the pictures. The coloring methods are flat coloring (Figure 20) and gradient rendering (Figure 21).

\subsection{Unique Form Beauty}

The art of Tibetan color paintings presents the beauty in form with strong regularity. This aesthetic feature is summarized and refined by Tibetan people after thousands of years of artistic activities, while painters inherit the art of architectural

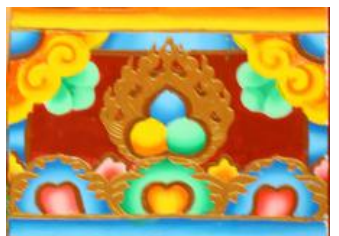

Figure 18. Flame pattern.

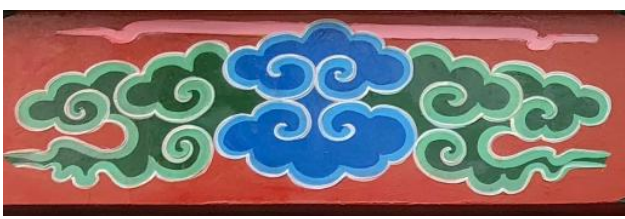

Figure 19. Cloud pattern.

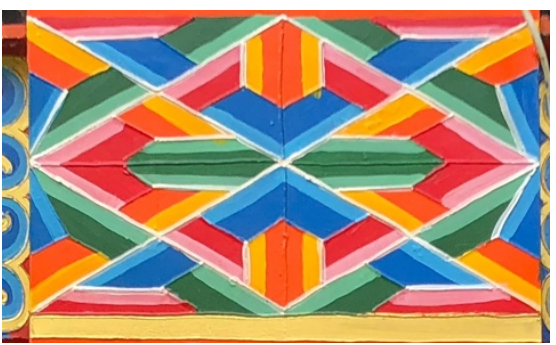

Figure 20. Flat coloring.

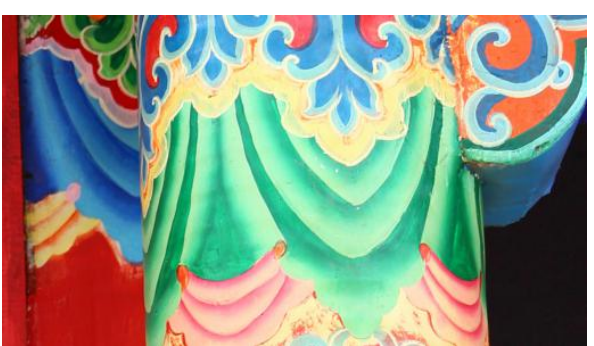

Figure 21. Gradual change. 
colored paintings by pass downing between masters and apprentices. The art of color painting in architecture is based on the function, originally for the purpose of "damp-proof, reinforcement and guidance" to protect the buildings. With the development of technology, the art of architectural colored paintings not only beautifies the appearance of buildings, but also expresses Tibetan humanistic thought, realizing the unity of function and aesthetics, while protecting the wooden components of buildings. Later, it gradually developed to the dominant position of aesthetic significance.

In terms of the pattern image, there are three types of patterns: simplified and abstract patterns, patterns with realistic scenes and legendary and fictional patterns. From the perspective of composition, first, the formal beauty of change and unity is embodied in the changes of the size, complexity and simplicity of patterns, and it is subject to the unified layout of the patterns on the entire component, reflecting the relationship between subject and object, reality and fiction. In coloring, the pattern changes and unifies as a whole, indicating the contrast between cold and warm, light and shade. Second, the formal beauty of orderliness and repetition is embodied in simplifying curling grass patterns of various shapes, showing the characteristics of complexity and orderliness, and establishing the sense of order of shapes. Third, the formal beauty of rhythm is embodied in the patterns through the contrast between loose and solid, bent and straight, sharp and smooth. Fourth, regardless of the size of the carrier, they are covered with various color paintings, reflecting a sense of richness and satiety.

\subsection{Meaning of Symbols}

Symbol refers to a mark or tab that is agreed by all members of a society to express a certain meaning, deriving from regulations or conventions. It has simple forms, a great variety and a wide range of purposes, with a strong artistic charm. Tibetan color painting art has its own special connotation, and different patterns represent different meanings. For example, fish is regarded as the eyes of Buddha in Tibetan culture, so fish means to discover wisdom, distinguish right from wrong, and stay away from ignorance. "Xixuan" (Tibetan "Gaji”) is similar to Tai Ji pattern in Han areas, but different from the symbolic meaning represented by Tai Ji pattern, Xixuan is the state of the universe and the law of things' development. Common Xixuan patterns are composed of three colors, representing the promotion of three forces. Every man's evil deeds are made up of "greed, hatred and ignorance", and we need to depend on three forces of "morality, meditation and wisdom" and three treasures of "Buddha, Dharma and Sangha" to free ourselves [5]. The figures created based on these representative symbols by means of abstract methods play a role in leading the people's spiritual world. Tibetan color painting art achieves the perfect combination of decorative and symbolic meanings.

\section{Design Cases of Street Furniture in Tibetan Areas}

The Tibetan people mainly live in the Qinghai-Tibet Plateau and the surrounding 


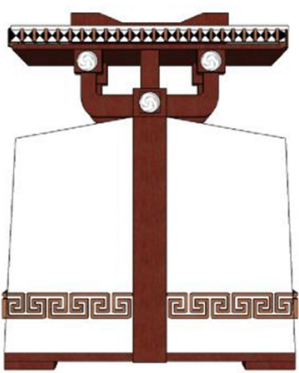

Poaitive view

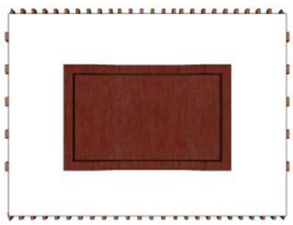

Top view

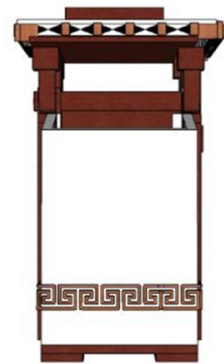

Left view

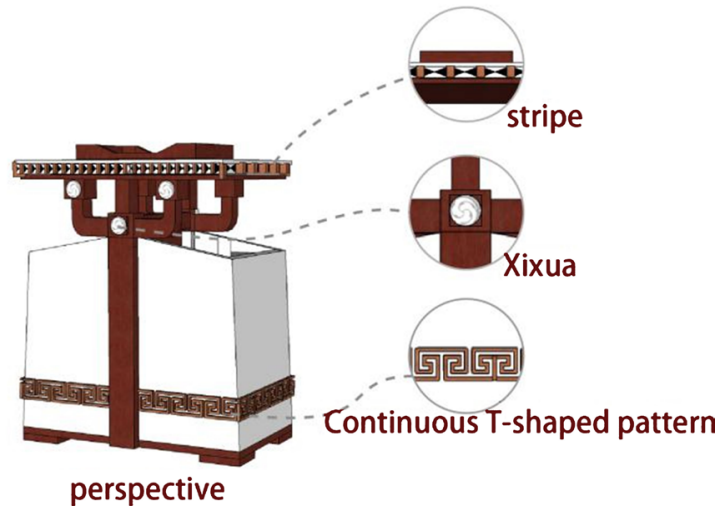

Figure 22. Design of garbage bin in Tibetan areas.

parts of Qinghai, Gansu and Sichuan provinces. In the cities inhabited by the Tibetan people, the construction of urban civilization and city image has also been put on the agenda [6] [7]. This paper explores the natural environment of cities in Tibetan areas, has an in-depth understanding of the Tibetan color painting art, and adheres to the people-oriented design concept, proceeds from the perspective of environmental protection, inherits Tibetan culture, and shapes the urban landscape environment with regional culture, so as to enhance the image and temperament of cities in Tibetan areas as the design objective. This scheme is preliminarily designed by applying the Tibetan color painting art to the design of street furniture (Figure 22), thus serving as a modest spur to the design of street furniture in Tibetan areas [8].

\section{Founding}

This project is funded by the graduate innovation research project of Southwest Minzu University, Project Name: Characteristics of Tibetan Color Painting Art and Its Application in the Design of Street Furniture, Project number: CX2019SZ182.

\section{Conflicts of Interest}

The author declares no conflicts of interest regarding the publication of this paper.

\section{References}

[1] Dorji, G. (2018) Types of Geometric Patterns and Their Cultural Interpretation in Tibetan Traditional Patterns. Tibetan Art Studies, No. 1, 11- 21.

[2] Dorji, G. (2018) The Development and Cultural Manifestation of the Animal Patterns in the Tibetan Traditional Decorative Patterns. Journal of Tibet University (Social Science Edition), 33, 96-109. 
[3] Wu, F.Y. (2013) Qing Dynasty Tibetan Official Painting Art Features and Innovative Application. Thesis, Northeast Forestry University, Harbin.

[4] Dorji, G. (2015) Tibetan Ornaments: Digital Tibetan Traditional Decorative Patterns. Tibet People's Publishing House, Lhasa.

[5] Liu, Z.G. and Zhang, S.Q. (2011) Study on the Color Drawing Patterns and Their Aesthetic Implications in Tibetan Architecture. Vertical and Horizontal Social Sciences, 26, 100-102.

[6] Shao, H. (2018) The Design for Urban Furniture under the Influence of Regional Factors. Journal of Shandong Agricultural University (Natural Science Edition), 49, 141-143.

[7] Liang, Y. (2015) Study on System Planning and Design of Urban Furniture. Thesis, China Academy of Art, Hangzhou.

[8] Li, C.J., Jiang, B.N. and Guo, X.J. (2013) Exploration and Analysis of Regional Design of Urban Furniture. Journal of Hebei Institute of Architectural Engineering, $31,37-41+48$ 